\title{
Reform and Construction of Energy and Power Engineering Courses
}

\author{
Xuefei LV ${ }^{1, \text { a }}$, Shukun GAN ${ }^{2, b^{*}}$ \\ 1,2College of Mechanical \& Electrical Engineering Jilin Institute of Chemical Technology \\ Jilin City, China
}

\begin{abstract}
In order to achieve the goal of applying undergraduate talent training, adapt to social development and follow the rules of teaching, and effectively improve the teaching effect. This paper combines the teaching experience and curriculum characteristics of the undergraduate majors of energy and power engineering for many years through the teaching reform and practice of the main courses of "fuel and combustion" and "thermal power plant pollution and control". The content of the two courses is rationally optimized and integrated, and comprehensive and systematic reforms and innovations are carried out from various aspects such as teaching content and teaching methods, thereby improving the quality of teaching and achieving the goal of talent training. Practice shows that the reformed curriculum has a significant effect on teaching, and can play a demonstration role in the curriculum construction of related majors.
\end{abstract}

Keywords-Energy and power engineering; Curriculum reform, Fuel combustion; Pollution control

\section{INTRODUCTION}

Energy is a top priority for all countries in the world, and the training of energy and power engineering professionals is particularly important. With the urgent demand for applied talents in society, relying on the reform of professional curriculum teaching will be an effective way to achieve the goal of professional applied talents.

"Fuel and Combustion" is a specialized discipline that studies the conversion of fuel chemistry to thermal energy. It is an important professional foundation course for energy and power. "Thermal Power Plant Pollution and Control" is a specialized course in the field of energy and power, and is a discipline that studies the formation and control of pollutants in fuel combustion. At present, $80 \%$ of the world's total energy comes from three major fossil fuels: coal, oil, natural gas, etc., and most of the pollutants and $\mathrm{CO} 2$ emissions are derived from combustion. Therefore, it plays an important role in energy conservation and emission reduction, such as efficient use of energy and effective control of pollutants. With the worldwide energy crisis and environmental problems becoming increasingly prominent, With the increasing energy crisis and environmental problems in the world, "burning" and "pollution control" as basic application research have received increasing attention from all walks of life [1-2].

Since the establishment of the energy and power engineering program, our school has developed a corresponding training program based on the professional setting of the National Teaching Steering Committee. "Fuel and Combustion" and "Thermal Power Device Pollution and Control" have become a professional compulsory course. A few years of teaching process, related course materials and the accumulation and construction of experimental textbooks, many related teaching resources have basically taken shape.With the increasing demand for applied technical talents in energy and power engineering in recent years, the adjustment of talent training programs and curriculum construction and reform are imperative. In 2016, the school unified the revision and improvement of the talent training program. The new training program should not only be guided by the new professional catalogue, but also combined with the strong provincial strategy formulated by the province to reduce the burden on students and improve student engineering. The quality, the principle of learning and use, and strive to cultivate high-quality engineering and technical personnel.In combination with the teaching practice, the energy and power engineering majors have also optimized and integrated the courses involved in the talent training program. This paper combines the "fuel and combustion science" and "thermal power plant pollution" in the original training program for several years. Control and practice the optimization and integration of the two professional courses into the teaching reform practice and effectiveness of the course "Fuel Combustion and Pollution Control".

\section{THE OVERALL THINKING OF CURRICULUM CONSTRUCTION}

The purpose of curriculum construction is to improve the quality of teaching. In the process of curriculum reform, the teaching thoughts should be consistent with the comprehensive training and improvement of modern science and technology, social and economic development, students' comprehensive quality and ability. Therefore, we should first determine the advanced Teaching ideas.

The guiding ideology of "Fuel combustion and pollution control" curriculum construction and reform is mainly based on the following two points: first, improve students' ability to analyze and solve problems, the second is to deepen students' understanding of the basic theory of combustion and pollution to lay a solid foundation for future study.

"Fuel and combustion" and "Thermal power device pollution and control" were originally two separate courses, 
which were set up in different semesters, and the content of the course was very relevant. "Fuel and combustion" was an examination course, 2.5 credits 40 hours, opened in the fifth semester, because the students in the exam class tend to pay more attention; "thermal power device pollution and control" for the examination class, 1.5 credits 24 hours, opened in the sixth semester, as a test student is often easy to ignore, making A lot of theoretical knowledge is not ideal. To solve this problem, the two courses are rationally integrated, that is, integrated into a course of "fuel combustion and pollution control", which is set as an examination course, 3 credits, 48 hours, and opened in the fifth semester.

According to the teaching experience of several years, optimize the teaching content, rewrite and outline, continuously enrich and improve the multimedia teaching courseware of the "Fuel combustion and pollution control" course, so that the course can better combine theory and practice in the teaching process. To improve students' understanding and understanding of theoretical applications.

This paper will mainly introduce the specific situation of the construction of "Fuel combustion and pollution control" course from six aspects: teaching content, teaching methods, teaching methods construction and assessment methods.

This paper will mainly introduce the specific situation of the construction of "fuel combustion and pollution control" course from six aspects: teaching content, teaching methods, teaching methods construction and assessment methods, etc.

\section{THE SPECIFIC CONTENT OF THE COURSE CONSTRUCTION}

\section{A. Optimize Teaching Content}

The research content of "Fuel and Combustion" mainly includes two aspects. On the one hand, the study of combustion theory, such as fuel ignition, flameout, flame propagation and flame stabilization, premixed flame, diffusion flame, laminar and turbulent combustion, droplet combustion, carbon particle combustion, formation of combustion products, etc. On the other hand, combustion technology, such as analysis and improvement of existing combustion methods, exploration and practice of new combustion methods, improve fuel utilization range and utilization efficiency, achieve control of the combustion process, and control pollutants in the combustion process. Generate and discharge, etc. [3-4]
The research content of "Thermal power device pollution and control" mainly includes four aspects, the formation and classification of combustion pollutants, the generation and decomposition of pollutants during combustion, and the exhaust pollution and control of boilers, internal combustion engines and gas turbine engines, and noise pollution and control, and so on.

From the main research contents of the two courses, it can be clearly seen that "Fuel and combustion" mainly focuses on theoretical knowledge and application, while the "Thermal power device pollution and control" course is about the control and governance of environmental pollution caused by the above theory and application, the two have inextricably linked.

The organic integration of "Fuel and combustion" and "Thermal power device pollution and control" into a "Fuel combustion and pollution control" course will inevitably cover the main content of the two courses, not only in streamlining the hours, but also through the course study enables students to fully grasp the theoretical knowledge and practical application of fuel combustion and pollution and control.

The main contents of the optimized "fuel combustion and pollution control" course include: energy classification and status, characteristics of the three major petrochemical fuels, basic combustion theory, basic combustion methods, formation and control of pollutants in the combustion process, etc.In the gas fuel, liquid fuel and solid fuel modules, in order to improve students' enthusiasm for learning, many aspects of combustion practice have been added, such as Bunsen burner flames for gas fuel combustion, domestic gas stoves and candle flames.There are diesel engines, oil-fired boilers and gas turbines; coal-fired boilers for solid fuel combustion, and waste incineration.At the same time, combined with the current development of scientific research frontiers, timely add some cutting-edge subject knowledge, such as micro-scale combustion technology, micro-gravity combustion technology,etc.It also explains the formation and control of pollutants in different combustion states under different combustion conditions, including emission standards for boilers and internal combustion engines, control of pollutants, etc., thereby increasing students' awareness of saving energy and protecting the environment. [5] The specific teaching content setting and time allocation before and after the course case are shown in Table 1, Table 2 and Table 3. 
TABLE I. T TEACHING CONTENT SETTING OF “FuEL AND COMBUSTION” BEFORE INTEGRATION

\begin{tabular}{|l|c|c|}
\hline Course nature & Test course & 1 \\
\hline & Introduction & 3 \\
& Introduction to fuel properties & 4 \\
& Fuel combustion calculation & 5 \\
Main content of the & Combustion reaction kinetics & 5 \\
course(hours) & Combustion airflow mixing process & 4 \\
& Flame propagation of gas combustion & 4 \\
& Gas fuel combustion method & 4 \\
& Stable characteristics of combustion flame & 3 \\
\hline
\end{tabular}

TABLE II. THE TEACHING CONTENT SETTING OF “THERMAL POWER DEVICE POLLUTION AND CONTROL” BEFORE INTEGRATION

\begin{tabular}{|c|c|c|}
\hline Course nature & \multicolumn{2}{|c|}{ Examination course } \\
\hline & Introduction & 2 \\
& Air pollution & 2 \\
& Formation and destruction of pollutants during combustion & 4 \\
Main content of the & Exhaust pollution and control of boilers and industrial furnaces & 4 \\
course(hours) & Internal combustion engine emissions and control & 4 \\
& Gas turbine engine exhaust pollution and control & 4 \\
& Noise pollution and control & 2 \\
& Numerical simulation of pollutant generation during combustion & 2 \\
\cline { 2 - 3 } & total & 24 \\
\hline
\end{tabular}

TABLE III. THE COURSE CONTENT SETTING"FUEL COMBUSTION AND POLLUTION CONTROL" AFTER THE INTEGRATION

\begin{tabular}{|c|c|c|}
\hline Course nature & Test course & 1 \\
\hline & Introduction & 5 \\
& Introduction to fuel properties & 6 \\
Main content of the & Fuel combustion calculation & 8 \\
course(hours) & Basic theory of combustion reaction & 8 \\
& Gas fuel combustion method and pollution control & 8 \\
& Liquid fuel combustion method and pollution control & 8 \\
& Solid fuel combustion method and pollution control & 4 \\
\hline
\end{tabular}

\section{B. Improve Teaching Methods}

In combination with the teaching content of the teaching experience of the course for several years, it is necessary to pay attention to the reform and practice of teaching methods in the teaching process.In teaching methods, we should pay attention to the theory and practice, especially when explaining the abstract theory in the "Fuel and Combustion" section. It should be easy to difficult and gradually explained in depth. Select some representative and more classic examples for detailed analysis when necessary.For some very important theoretical knowledge points, fuel combustion thermochemistry, chemical kinetics, and combustion theory of gaseous fuels, liquid fuels, and solid fuels are all involved.In addition, the composition, content and formation mechanism of pollutants produced by the fuel in the combustion process are different, especially the mechanism of pollutant formation [6]. The difficulty depth should be arranged reasonably during the explanation process, and the key content is in the process of explanation. It should be in-depth and meticulous, taking more hours of study, allowing students to master the knowledge points to the maximum extent, and lay a solid theoretical foundation for future work and study.

In order to further inspire students' independent thinking ability, to integrate knowledge, and let students feel the practicality of knowledge, we must also pay attention to the abstract theory and reality in the book.For example, when learning the theory of fire and flameout, contact the gas 
explosion in the mine and the invention principle of the early miner's lamp;Introducing the latest technologies in desulfurization, denitrification, and $\mathrm{CO} 2$ reduction and storage, such as modern coal-fired boilers, fuel-fired internal combustion engines, and gas turbine engines, when introducing pollutant emissions and control in fuel combustion processes.And guide students to explain these new technologies from the perspective of combustion principles, and so on.In addition, in order to better activate the classroom atmosphere, some simple experiments are demonstrated in the classroom teaching. Such as demonstrating the lighter, the flame of matches, etc., let the students observe the difference in flames, and explain these differences in combination with combustion knowledge.Through small experiments, students' enthusiasm for learning and their ability to analyze and explore practical problems are greatly improved.

\section{Innovative Teaching Methods}

The "Fuel Combustion and Pollution Control" course uses multimedia lectures to make full use of modern multimedia network technology to produce multimedia teaching courseware with animations such as Flash.In order to strengthen the interaction between teachers and students in the classroom, in the multimedia teaching, the traditional combination of traditional blackboard teaching methods is combined.For example, the more complex theorem formula should be deduced as much as possible on the blackboard; the relatively complex abstract course content should be explained in the form of Flash animation as much as possible, and presented to the students in detail and vividly, thus combining the perceptual knowledge with the rational understanding. It promotes students' understanding and mastery of complex abstract classroom content [7]. After years of continuous improvement and summarization, the course has formed a relatively complete multimedia courseware.Through the integration and reform of this course, these multimedia coursewares are not only illustrated, but also rich in content and large amount of information, which has a strong enlightenment effect on students. Through the combination of multimedia technology and traditional blackboards, students can create a relaxed and pleasant learning environment, thus improving students' enthusiasm for learning, and the teaching effect will be significantly improved [8].

\section{Reform Assessment Methods.}

The"Fuel Combustion and Pollution Control" course is set up as an examination course. The results are based on a variety of assessment methods, which are weighted by the usual grades and final exam scores.Ordinary grades (including homework assignments, attendance, quizzes, etc.) account for $30 \%$ of the total grade, of which assignments account for $10 \%$ of the total grade. The score of the quiz is $10 \%$ of the total score. the attendance is $10 \%$ of the total score. For students who are late, early leave, and absent from school, the attendance results should be properly deducted.At the same time, students' creative thinking development and incentive mechanisms are encouraged to give extra points to students who have creatively solved related problems in the learning process.
The final exam is a closed-book exam, accounting for $70 \%$ of the total score at the end of the period. The examination papers are uniformly issued by the classroom teachers. The school uniformly arranges the examination time and place. This assessment method can more accurately reflect the students' learning situation. The final exam questions are divided into five types of questions: fill in the blanks, select, judge, analyze short answers and calculate questions.Filling in the blanks, selection and judgment questions can assess students' mastery of basic combustion theory and pollution control. The analysis of short-answer questions assesses students' ability to use the knowledge they have learned to solve practical problems, while the calculation questions assess students' engineering calculations for fuel combustion.And through the gradual accumulation in the teaching process, the corresponding test questions library is established.

Through the setting of these assessment methods, the pressure on students in the final exam can be significantly reduced, and the phenomenon of not attending classes and temporary surprises in examinations can be reduced.

\section{CONCLUSION}

"Fuel Combustion and Pollution Control" is an important course in the energy and power category. Through the revision of the syllabus during the course construction process, with the continuous enrichment of teaching methods, the continuous updating of teaching methods, and the continuous improvement of multimedia courseware, students The enthusiasm for learning will inevitably improve, the teaching effect will continue to improve, students can better grasp the theoretical knowledge of the formation and control of pollutants in fuel combustion and combustion process, and learn to use.Through the practical setting and implementation of the theoretical and practical aspects of the curriculum, students' theoretical level and engineering practice ability and quality will be improved. At the same time, it will provide a powerful reference for the teaching reform and practice of relevant professional courses and the improvement of professional teaching level. With a wide range of applications and promotional value.

\section{REFERENCES}

[1] S.C.HAN,Fuel and Combustion(Metallurgical Industry Press, China 1993).

[2] L.X.ZHOU,Combustion Theory and Chemical Fluid Dynamics(Science Press,China 1986).

[3] J.X.ZHAO,S.F.WANG,Y.LIU.Exhaust Pollution and Noise of Thermal Power Units(Science Press, China 2008).

[4] K.F.QIN,Q.YAO,Z.Y.LUO,Combustion Theory and Pollution Control(Mechanical Industry Press, China 2004).

[5] Stephen R.Turns. An Introduction to Combustion (Conceptsand Application ,New York, McGraw-Hill International,1996).

[6] Y.C.CAO,J.X.WU,C.L.JIAO,China Electric Power Education, (2010)No.4,p.69-71.

[7] L.SU,China Science and Education Innovation Guide, (2009) No.34,p.134.

[8] B.W.WANG,W.S.WANG,C.C.GAO,China Electric Power Education,(2010)No.30,p.100-102. 